\title{
Transmission System of Go-Kart
}

\author{
Ch. Rajendra Prasad ${ }^{1}$, Mohammed Feroz Ahmed ${ }^{2}$, Md Khader Mohiuddin ${ }^{3}$ \\ Assistant Professor, Mechanical Department, Lords Institute of Engg \& Tech, Hyderabad, India ${ }^{1,2}$ \\ Student, Mechanical Department, Lords Institute of Engg \& Tech, Hyderabad, India ${ }^{3}$
}

\begin{abstract}
Go-kart, by definition, has no suspension and no differential. They are usually raced on scaled down tracks, but are sometimes driven as entertainment or as a hobby by non-professionals. 'Carting is commonly perceived as the stepping stone to the higher and more expensive ranks of motor sports. Kart racing is generally accepted as the most economic form of motor sport available. As a free-time activity, it can be performed by almost anybody and permitting licensed racing for anyone from the age of 8 onwards. Kart racing is usually used as a low-cost and relatively safe way to introduce drivers to motor racing. Many people associate it with young drivels, but adults are also very active in karting. Karting is considered as the first step in any serious racer's career. It can prepare the driver for highs-speed wheel-to-wheel racing by helping develop guide reflexes, Precision car control and decision-making skills. In addition, it brings an awareness of the various parameters that can be altered to try to improve the competitiveness of the kart that also exist in other forms of motor racing.
\end{abstract}

Keywords: transmission, go-kart, final drive sprocket, gear.

\section{INTRODUCTION}

A transmission is a device or machine that consists of power source and power transmission system, which provides controlled application of the power. Often the term transmission refers simply to the gear box that uses gears and gear trains to provide speed and torque conversion from a rotating power source to another machine device.

The dynamics of a car vary with speed: at low speeds, acceleration is limited by the inertia of vehicular gross mass; while at cruising or maximum speeds wind resistance is the dominant barrier. When changing gear, The engine torque is transferred from one gear to the other continuously, so providing gentle, smooth gear changes without either losing power or jerking the vehicle.

\section{DESIGN METHODOLOGY}

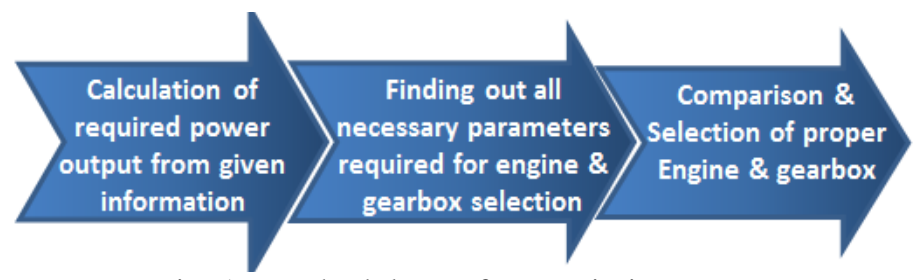

Fig. 1. Methodology of transmission system

\section{TRANSMISSION SYSTEM}

A. Goals

The main function of a transmission system is to ensure uninterrupted movement of the wheels with help of motor. The hope for the transmission system to be design was

To achieve maximum possible speed using gears.

- $\quad$ To achieve maximum torque at the starting and continues.

- $\quad$ With a possible extent, to reduce the major and minor power losses.

- $\quad$ Selecting of components carefully to avoid the power losses and to overcome the above view.

- $\quad$ To achieve high torque at low rpm.

- To achieve high efficiency.

B. Engine Selection

An engine of a go-kart is usually a small one. About 100-200cc.so this kart, we use a BAJAJ PULSAR Single Cylinder $135 \mathrm{cc} 4$-stroke petrol engine, which produces about $13 \mathrm{BHP}$ of power at $9000 \mathrm{rpm}$. We use 4- stroke engine because this is used for racing and good mileage also.

We choose the BAJAJ PULSAR $135 \mathrm{cc}$ engine according to comparisons with other scooters. 
1) Engine Specifications

- Engine Type: 4 stroke single cylinder

- Cooling: Air cooled

- Displacement: $134.66 \mathrm{cc}$

- Bore x Stroke: 54 x $58.8 \mathrm{~mm}$

- Compression Ratio: 9.2: 1

- Max. Power: 13.56 BHP @ 9000 RPM

- Max. Torque: 11.4 Nm @ 7500 RPM

- Ignition : digital twin spark ignition system

2) Clutch and Transmission

- Gear Box: 5 speed constant mesh with the following ratios:

- 1 st -3.076

- 2 nd - 1.944

- $3 \mathrm{rd}-1.473$

- 4 th -1.190

- 5 th -0.9583

- Primary Reduction Ratio (P): 3.350

- Clutch Type: Wet multi plate

C. Calculations

1. Final Drive Ratio (F): Obtaining a higher torque at the wheels is our priority, which means reducing the top speed. However it is a compromise because it reduces fuel economy.

Tire radius $=(\mathrm{r})=139.7 \mathrm{~mm}$

$\mathrm{S}=118 \mathrm{kmph}$

$=>\omega=\mathrm{v} / \mathrm{r}=1235 \mathrm{RPM}$ (At the wheels)

Engine RPM = 10 redn. Ratio $x$ 5th gear ratio $\times \mathrm{F} \times \mathrm{S}$

$\mathrm{F}=1.86$, which is the final drive ratio.

Drive sprocket diameter $=10.6 \mathrm{~cm}$

2. Shaft Diameter and Angle of Twist

Torque at drive axle,

$\mathrm{T}=$ Engine torque $\mathrm{x}$ Primary Reduction Ratio $\mathrm{x}$ First Gear Ratio $\mathrm{x}$ Final Drive Ratio

$\mathrm{T}=210.83 \mathrm{Nm}$

T/Working Stress $=\pi \mathrm{d}^{3} / 3$

Considering a $30 \mathrm{~mm}$ dia. mild steel shaft,

Working stress $=65.78 \mathrm{MPa}$

Factor of safety = Max Stress/ Working Stress

$\mathrm{FOS}=2.28$

Stress $/$ Radius $=$ Rigidity Modulus $\times$ Angle of twist $/$ Length

Angle of Twist $=0.071 \mathrm{rad}$, or 4.06 degrees

The maximum speeds attainable by the kart in different gear

3. Tractive force: umg

$$
\begin{aligned}
& =0.6 * 140 * 9.81 \\
& =824.04 \mathrm{~N}
\end{aligned}
$$

4. Starting torque: $\mathrm{FT}^{*} \mathrm{R}$

$$
\begin{aligned}
& =824.04 * 0.27 \\
& =225.786
\end{aligned}
$$

5. Velocity

$=$ Engine $\mathrm{rpm}^{*}$ wheel tire perimeter/ gear ratio *axle ratio

$=9000 * 60 * 3.14 * 2 * 11 * 25.4 * 0.000001 / 2 * 4$

$=118.43 \mathrm{kmph}$

\section{WHEEL ASSEMBLY}

\section{A. Introduction}

1) Selection

Tires are the important part which takes the load of the vehicle and provides tractive forces to move the vehicle thorough survey was made on the availability of different tires suitable for a go kart. It was decided to use standard go kart traded tires which available in the market which provide better traction on dry and wet conditions. The rear tires 
are wider and bigger in diameter than the front tires as the load is biased towards the rear and to minimize rolling resistance.

B. Goals

- To provide maximum grip at the tires.

- To transmit power from the shaft to the rear wheels with minimal power loss.

C. Front wheel assembly

Front wheel assembly comprises of hubs, and wheels. The arms are connected to the hub which is connected to the wheels which is welded on to the chassis. The fixture provides adjustability in caster angle. The dimensions are so chosen that there is no interference between the steering components and the chassis in the dynamic condition. The 3D simulation of the steering mechanism was done in the solid works

The dimensions and the inclination of the steering link are so chosen that it adheres to the kinematics of steering designed. It is designed to accommodate the wheel hub and a positive stop is provided to secure the hub in place.

TABLE. I FRONT WHEELS SPECS

\begin{tabular}{|c|c|}
\hline Tire & Standard go-kart traded tires \\
\hline Wheel diameter & $10 "$ \\
\hline Wheel width & $4.5 "$ \\
\hline Rim diameter & $5 "$ \\
\hline
\end{tabular}

D. Rear wheel assembly

The rear wheel assembly comprises of a single shaft, hubs, bearing unit and wheels.

TABLE.II REAR WHEEL SPECS

\begin{tabular}{|c|c|}
\hline Tire & Standard go-kart traded tires \\
\hline Wheel diameter & $11 "$ \\
\hline Wheel width & $7.10^{\prime \prime}$ \\
\hline Rim diameter & $5 "$ \\
\hline
\end{tabular}

\section{CONCLUSION}

In this work, a detailed methodology of the virtual design and testing has been presented including the reasoning of using the materials used for the fabrication of the chassis and axle. Also, the reasoning of fabrication of new chassis design of go-kart which is different than the chassis design of the standard Go-Kart has been given and proven. Even if the entire process of design and testing proposed has shown interesting results but methodology must be still validated through dynamic experimental tests. This will allow the creation of mathematical model completely defined and validated, giving the basis of future developments regarding the optimization process of go-kart performance.

\section{ACKNOWLEDGEMENT}

We would like to thank our college, Lords Institute of Engineering \& Technology, Hyderbad for providing us with moral support and different lab facilities. Also, we would like to thank the Head of Department (Department of Mechanical Engineering) Dr. Syed Azam Pasha Quadri We would also thank Mr. Mohammed Feroz Ahmed(Assistant Professor Dept. of Mechanical Engineering) and Mr. Ch Rajendra Prasad (Assistant Professor Dept. of Mechanical Engineering) for providing us with mentorship.

\section{REFERENCES}

[1] PTC Pro Engineer Wildfire 2.0 User's Guide

[2] MIRONE, Giuseppe. Mulibody modelisation of a Go-Kart with flexible frame: simulation of the dynamic behavior and experimental validation. SAE International, 2003

[3] Design Data Handbook Vol I and Vol II, Prof. Lingiah, University College of Engineering, Bangalore

[4] Design of Machine Elements - I, Prof. J B K Das 